\title{
STUDI PEMANFAATAN CATU DAYA HIBRIDA PLTS 3,7 KWP DAN PLN PADA INSTALASI PENGOLAHAN AIR LIMBAH DESA PEMECUTAN KAJA DENPASAR BALI
}

\author{
P A R Arimbawa 1, I N S Kumara 2, R S Hartati 3
}

\begin{abstract}
Pemecutan Kaja waste treatment plant (WTP) is a community treatment plant located in one of Denpasar city ward to process sewerage produced by community members. The WTP uses radial flow anaerobic system which mainly consists of rabic pro tank and up flow tank. The water produced by the WTP is released to nearby river as it already meet envinronmental quality standard. The WTP is driven by an electric pump to circulate sewer material within the process flow. The pump was fed by hybrid power supply combining $3.7 \mathrm{~kW}$ solar PV and power from utility grid. The WTP is operated by village council of Pemecutan Kaja. The study presented here is result of firstly, evaluation on the utilization and performance of solar PV plant, and secondly, to propose managerial model can be manage the plant effectively and sustainably. The study found that daily average energy produced by the PVplant is $23.59 \mathrm{kWh}$ yielding cost of energy at IDR $7,766 / \mathrm{kWh}$. Experiment to clean filters of the plant reduced daily energy consumption from 8.84 kWh to $3.05 \mathrm{kWh}$ or $65 \%$. Household that connected to the plant pay monthly subscription currently at IDR 10,000 . However, for sustainable operation of the plant, the household need to pay IDR 51,654.
\end{abstract}

Keywords - Renewable Energy, Solar PV, Hybrid Power Supply, Waste Treatment, Managerial Model

Intisari- Instalasi Pengolahan Air Limbah (IPAL) Desa Pemecutan Kaja adalah IPAL yang terletak di salah satu lingkungan kota Denpasar yang berfungi untuk mengolah air limbah yang dihasilkan oleh anggota masyarakat. IPAL ini meggunakan sistem radial flow anaerobic yang terdiri dari rabic pro tank dan up flow filter tank. Air hasil pengolahan limbah dapat langsung disalurkan ke sungai karena sudah memenuhi baku mutu limbah cair. IPAL ini menggunakan pompa listrik untuk mengalirkan limbah menuju tangki penyaringan. Pompa ini menggunakan catu daya hibrida PLTS 3,7 kW dan PLN. IPAL ini dikelola langsung oleh masyarakat desa Pemecutan Kaja. Hasil penelitian yang ingin dicapai adalah pertama, evaluasi pemanfaatan dan kinerja PLTS, kedua merencanakan model pengelolaan agar IPAL dapat berfungsi secara optimal dan berkelanjutan. Hasil penelitian ini menemukan bahwa ratarata energi listrik yang dihasilkan PLTS yaitu $23,59 \mathrm{kWh} / \mathrm{hari}$ dengan harga energi sebesar Rp.7.766,25/kWh. Percobaan untuk membersihkan filter pada IPAL dapat mengurangi konsumsi energi harian dari $8,84 \mathrm{kWh}$ menjadi $3,05 \mathrm{kWh}$ atau $65 \%$. Rumah tangga yang menjadi pengguna IPAL saat ini membayar

${ }^{I}$ Mahasiswa, Program Studi Magister Teknik Elektro, Program Pasca Sarjana, Universitas UdayanaJl. Panglima Besar Sudirman Denpasar, Bali (Email: aris.ridhana@yahoo.com)

${ }^{2,3}$ Staf Pengajar Program Magister Teknik Elektro, Program Pascasarjana, Universitas Udayana Jl. Panglima Besar Sudirman Denpasar, Bali iuran sebesar Rp 10.000. Namun, untuk operasi yang berkelanjutan dari IPAL, rumah tangga perlu membayar sebesar Rp 51.654.

Kata kunci- Energi Terbarukan, PLTS, Pembangkit Listrik Hybrid, Pengolahan Limbah, Model Pengelolaan

\section{PENDAhULUAN}

Indonesia terletak pada daerah khatulistiwa sangat potensial untuk mengembangkan sumber energi matahari sebagai sumber energi alternatif. Energi matahari digunakan untuk menggantikan energi konvensional yang persediaannya mulai menipis [1]. Indonesia memiliki potensi energi listrik surya sebesar 4,5 kW/m2/hari [2].

Pemanfaatan tenaga matahari untuk pembangkitan listrik di Indonesia sudah dilakukan sejak awal dekade 80-an, tetapi aplikasinya masih terbatas pada sistem berdaya kecil atau yang lebih dikenal dengan Solar Home System (SHS) [3]. Sejalan dengan Kebijakan Energi Nasional (KEN) dalam pengelolaan energi nasional, Pembangkit Listrik Tenaga Surya (PLTS) dikembangkan untuk meningkatkan peran energi terbarukan dalam pembangkitan energi listrik nasional. PLTS memiliki keunggulan yaitu ketersediaan sumber energi matahari yang tidak pernah habis, pengoperasian PLTS yang ramah lingkungan atau tidak mengeluarkan polusi, dan dapat di bangun secara swadaya sesuai dengan kemampuan dan kebutuhan.

Penelitian tentang $1 \mathrm{MWp}$ Grid Connected PV Systems In The Village Of Kayubihi Bali; Review On Location's Characteristics And Its Technical Specifications menunjukan Bali sebagai daearah tropis yang dekat garis khatulistiwa yang memiliki kuantitas yang berlimpah akan energi matahari dengan indeks insolasi matahari diperkirakan antara 5 sampai $6 \mathrm{kWh}$ per meter persegi setiap hari [4]. Sistem ini memiliki keunggulan ramah lingkungan dan waktu pembangunan yang relatif singkat. Sistem ini merupakan sistem yang terbesar di indonesia terhubung dengan jaringan distribusi $20 \mathrm{kV}$.

Penelitian tentang On The Potential And Progress Of Renewable Electricity Generation In Bali menunjukan. Bali tidak memiliki sumber daya konvensional karena bahan bakar berbasis fosil bersumber dari luar pulau Bali [5]. Untungnya, Bali memiliki berbagai sumber daya terbarukan yang dapat dimanfaatkan untuk pembangkit listrik. Energi terbarukan menyumbang sekitar $1 \%$ yaitu 7MW dari total kapasitas listrik di Bali dengan komposisi 2,1 MW tenaga surya, $736 \mathrm{~kW}$ tenaga angin, $45 \mathrm{~kW}$ mikro hidro, dan 4,174 MW tenaga limbah/sampah. 
Penelitian tentang Analisis Unjuk Kerja Pembangkit Listrik Tenaga Surya (PLTS) Satu MWP Terinterkoneksi Jaringan di Kayubihi Bangli menunjukan Potensi optimum energi listrik per tahun yang dihasilkan PLTS Kayubihi dari hasil simulasi adalah $1656 \mathrm{MWh}$, dengan unjuk kerja/rasio performa 83,6 \% [6]. Berdasarkan waktu operasi dari 15 Februari s.d. 30 September 2013 produksi real energi listrik PLTS Kayubihi adalah 729,08 MWh, selisih 32,3\% dari simulasi PV System sebesar 1076,94 MWh. Shading dan gangguan yang ada menurunkan produksi energi dan unjuk kerja spesifik PLTS Kayubihi yaitu YF 3,20 jam/hari, dengan faktor kapasitas (CF) 13,34 \% terhadap simulasi, yaitu YF 4,68 jam/hari dan CF 19,53\%

Penelitian tentang Configuration Hybrid Solar System $(P V)$, Wind Turbine, And Diesel menunjukan penggunaan energi terbarukan dalam pembangkitan energi listrik mulai dikembangkan dan terus ditambah kapasitasnya dengan cara diparalel dengan diesel atau pembangkit konvensional yang ada [7]. Kombinasi tenaga surya atau photovoltaik ( $P V)$ dan diesel generator hybrid adalah yang paling banyak dipasang.

Penelitian tentang Studi Pemanfaatan Pembangkit Listrik Tenaga Surya Sebagai Catu Daya Tambahan Pada Industri Perhotelan Di Nusa Lembongan Bali menunjukan sistem PLTS yang akan dikembangkan untuk mensuplai energi listrik hotel yang direncanakan sebesar 30 persen, adalah sistem PLTS yang hybrid dengan suplai listrik PLN [8]. Alternatif strategi dari analisis SWOT menunjukkan bahwa penetapan regulasi dari pemerintah sangat berperan dalam pemanfaatan PLTS sebagai catu daya tambahan, layak untuk dikembangkan pada industri perhotelan di Nusa Lembongan khususnya pada hotel Bali Hai Tide Huts.

Berdasarkan beberapa hasil penelitian di Bali berpotensi untuk dikembangkan pembangkit listrik energi terbarukan yaitu PLTS. Penggunaan energi terbarukan dalam pembangkitan energi listrik mulai dikembangkan dan terus ditambah kapasitasnya dengan cara diparalel dengan diesel atau pembangkit konvensional yang ada. Sistem hibrida yang paling banyak dikembangkan adalah sistem hibrida PLTS dengan PLN. Berdasarkan alternatif strategi dari analisis SWOT pemanfaatan pembangkit listrik tenaga surya sebagai catu daya tambahan pada industri perhotelan di Nusa Lembongan Bali menunjukkan bahwa penetapan regulasi dari pemerintah sangat berperan dalam pemanfaatan PLTS sebagai catu daya tambahan, layak untuk dikembangkan.

Desa Pemecutan Kaja merupakan desa yang menjadi percontohan di wilayah Kota Denpasar dalam pengolahan air limbah. Di desa ini telah dibangun Instalasi Pengolahan Air Limbah (IPAL) rumah tangga dengan pendanaan dari APBD Kota Denpasar. IPAL ini digunakan untuk mengolah limbah rumah tangga dari dua banjar yaitu Banjar Merthayasa dan Banjar Tulang Ampiang. IPAL ini meggunakan sistem radial flow anaerobic. Sistem ini terdiri dari dua buah tangki penyaringan yaitu tangki rabic pro dan tangki up flow filter. Air hasil pengolahan limbah dapat langsung disalurkan ke sungai karena sudah memenuhi baku mutu limbah cair.

IPAL ini menggunakan sistem catu daya hibrida PLTS dengan PLN. Kapasitas catu daya terpasang PLN 7.700 VA dan PLTS 3.740 Wp. Sistem ini menggunakan PLTS sebagai catu daya utama dan PLN sebagai catu daya cadangan. Sistem ini dilengkapi dengan Automatic Transfer Switch untuk

P A R Arimbawa: studi pemanfaatan catu daya .......... memindahkan penggunaan catu daya utama dengan catu daya cadangan. Pada tahun 2014 pengelolaan IPAL ini dikelola langsung oleh Desa Pemecutan Kaja. Sejak awal pengoperasian PLTS ini, belum pernah dilakukan penelitian tentang kinerjanya. Untuk pemeliharaan sistem, belum pernah dilakukan perawatan dan kelompok kerja desa hanya melakukan pengisian pulsa agar daya dari PLN dapat tetap tersuplai. Kurangnya pengetahuan tentang pengoperasian PLTS dan belum dilakukannya pengkajian tentang konsumsi energi di IPAL menjadi kendala dalam pengelolaan IPAL secara optimal dan berkelanjutan. Dalam penelitian ini dilakukan studi pemanfaatan catu daya hibrida PLTS dan PLN di IPAL Desa Pemecutan Kaja yang mencakup produksi energi listrik dari PLTS dan PLN, biaya produksi energi listrik PLTS dan model pengelolaannya sehingga IPAL dapat beroperasi secara optimal dan berkelanjutan.

\section{Plts 3,7 Kwp Di Ipal Desa Pemecutan KaJA}

Pembangkit Listrik Tenaga Surya (PLTS) adalah pembangkit yang mengkonversikan energi foton dari surya menjadi energi listrik. Konversi ini terjadi pada panel surya yang terdiri dari sel-sel photovoltaik. Sel-sel ini terdiri dari lapisan-lapisan tipis dari silikon ( $\mathrm{Si}$ ) murni dan bahan semi konduktor lainnnya [9].

Sistem pembangkit listrik tenaga surya (PLTS) mempunyai beberapa komponen diantaranya adalah solar module (module photovoltaics), baterai, change controller (Regulator), inverter, kabel instalasi [10]. Komponenkomponen PLTS yang terpasang di IPAL ini adalah

1. Solar module (module photovoltaics)

Modul Photovoltaic yang terpasang di IPAL ini adalah Solar World sebanyak 44 modul yang dihubungkan secara seri dan paralel. Kapasiats modul photovoltaic pada kondisi standar adalah 85 wp (watt-peak) dengan rated curent (Impp) 4,95 ampere dan rated voltage (Vmpp) 17,2 Volt.

2. Baterai

Kapasitas baterai yang digunakan adalah 1.260 Ah dengan tegangan 2 volt DC. Jumlah baterai yang digunakan adalah sebanyak 24 buah. Tegangan sistem yang digunakan 24 volt, sehingga baterai dirangkai seri masing-masing sebanyak 12 buah kemudian barulah dirangkai secara paralel. Kapasitas maksimum baterai menjadi 30.240 Ah.

3. Change Controller (Regulator)

Battery Charger Controller yang digunakan di IPAL ini adalah Staca Tarom 440.

4. Inverter

Inverter yang digunakan adalah Steca Xtender XTM 350024. Pada bulan agustus 2014 iverter yang terdapat di IPAL ini mengalami gangguang yang diakibatkan oleh terbakarnya pompa. Terbakarnya pompa mengakibatkan inverter tidak dapat digunakan kembali. Selama waktu penelitian ini inverter yang digunakan untuk pengambilan data adalah inverter lokal.

5. Kabel Instalasi

Kabel yang digunakan untuk instalasi PV adalah kabel khusus yang dapat mengurangi loss (kehilangan) daya, pemanasan pada kabel, dan kerusakan pada perangkat.

p-ISSN:1693 - 2951; e-ISSN: 2503-2372 


\section{Metode Penelitian}

Penelitian ini dilakukan di Instalasi Pengolahan Air Limbah (IPAL) Desa Pemecutan Kaja, Kota Denpasar, Bali. Waktu penelitan dari Juni 2014 sampai dengan Mei 2015. Langkah-langkah dalam penelitian ini adalah me-review sistem IPAL Desa Pemecutan Kaja yang terdiri dari sistem kerja IPAL dan kendala dalam pengelolaan IPAL. Me-review sistem catu daya di IPAL Desa Pemecutan Kaja yang terdiri dari konfigurasi sistem PLTS dan komponen PLTS. Pengambilan data-data PLTS dengan pengukuran konsumsi energi listrik harian di IPAL, pengukuran daya dan energi listrik yang dihasilkan PLTS dan pengukuran konsumsi energi listrik PLN di IPAL Desa Pemecutan Kaja. Analisa kinerja sistem PLTS di IPAL Desa Pemecutan Kaja yang terdiri dari analisis produksi energi PLTS, faktor-faktor yang mempengaruhi produksi energi listrik.dan menganalisis persentase energi yang dihasilkan PLTS dan PLN dalam memenuhi kebutuhan energi listrik di IPAL Desa Pemecutan Kaja. Menyusun model pengelolaan IPAL Desa Pemecutan Kaja agar dapat beroperasi secara optimal dan berkelanjutan yang terdiri dari SDM (Sumber Daya Manusia), manajemen pengelolaan dan iuran perbulan masyarakat yang diperoleh dari biaya siklus hidup (Life Cycle Cost) sistem yang dibagi dengan jumlah pengguna rumah tangga.

Pengelolaan PLTS melalui partisipasi masyarakat merupakan salah satu upaya untuk memberdayakan potensi masyarakat dalam merencanakan pembangunan yang berkaitan dengan potensi sumber daya lokal berdasarkan kajian musyawarah yaitu peningkatan aspirasi berupa keinginan dan kebutuhan nyata yang ada dalam masyarakat, peningkatan motivasi dan peran-serta kelompok masyarakat dalam proses pembangunan, dan peningkatan rasa-memiliki pada kelompok masyarakat terhadap program kegiatan yang telah disusun.

Salah satu metode yang dapat digunakan untuk pembentukan lembaga pengelola pembangkit energi terbarukan adalah Participatory Action Research (PAR) [11]. Metode ini lebih menekankan pada partisipasi komunitas dalam menyelesaikan suatu masalah dengan berdasarkan pada kondisi sosial setempat. Dalam metode PAR ada empat langkah yang harus diterapkan dalam menyelesaikan suatu masalah, yaitu identifikasi masalah (problem identification), pengumpulan informasi (information collection), aksi (action) dan evaluasi (evaluation).

Iuran perbulan masyarakat dihitung dari biaya siklus hidup (Life Cycle Cost) sistem yang dibagi dengan jumlah pengguna rumah tangga. Biaya siklus hidup merupakan semua biaya yang dikeluarkan oleh suatu sistem, selama kehidupannya. Pada sistem PLTS, biaya siklus hidup (LCC) ditentukan oleh nilai sekarang dari biaya total sistem PLTS yang terdiri dari biaya investasi awal, biaya jangka panjang untuk pemeliharaan dan operasional serta biaya penggantian baterai [12][8]. Biaya siklus hidup (LCC) diperhitungkan dengan rumus sebagai berikut:

$\mathrm{LCC}=\mathrm{C}+\mathrm{MPW}+\mathrm{RPW}$

Nilai sekarang biaya tahunan yang akan dikeluarkan beberapa waktu mendatang (selama umur proyek) dengan jumlah pengeluaran yang tetap, dihitung dengan rumus sebagai berikut:

$P=A\left[\frac{(1+i)^{n}-1}{i(1+i)^{n}}\right]$

Biaya pemeliharaan dan operasional per tahun untuk PLTS umumnya diperhitungkan sebesar 1-2\% dari total biaya investasi awal [13][14][8]. Perumusan biaya energi adalah sebagai berikut 12][8]:

$C O E=\frac{L C C X C R F}{A K W H}$

Faktor pemulihan modal, berdasarkan pada discount rate (i). Dihitung dengan rumus berikut dengan $\mathrm{n}$ adalah periode (umur) proyek.

$C R F=\frac{i(1+i)^{n}}{(1+i)^{n}-1}$

\section{HASIL DAN PEMBAHASAN}

\section{A. Gambaran Umum IPAL Desa Pemecutan Kaja}

IPAL Desa Pemecutan Kaja merupakan percontohan di wilayah Kota Denpasar dalam pengolahan air limbah. Pembangunan IPAL ini bertujuan untuk meningkatkan kesehatan lingkungan masyarakat sebagai antisipasi terhadap penurunan kualitas lingkungan dan meningkatkan kesadaran masayarakat dalam memelihara lingkungan. IPAL Desa Pemecutan Kaja digunakan untuk mengolah limbah rumah tangga dari dua banjar yaitu Banjar Merthayasa dan Banjar Tulang Ampiang. Sampai saat ini jumlah pengguna IPAL sudah mencapai $70 \mathrm{KK}$.

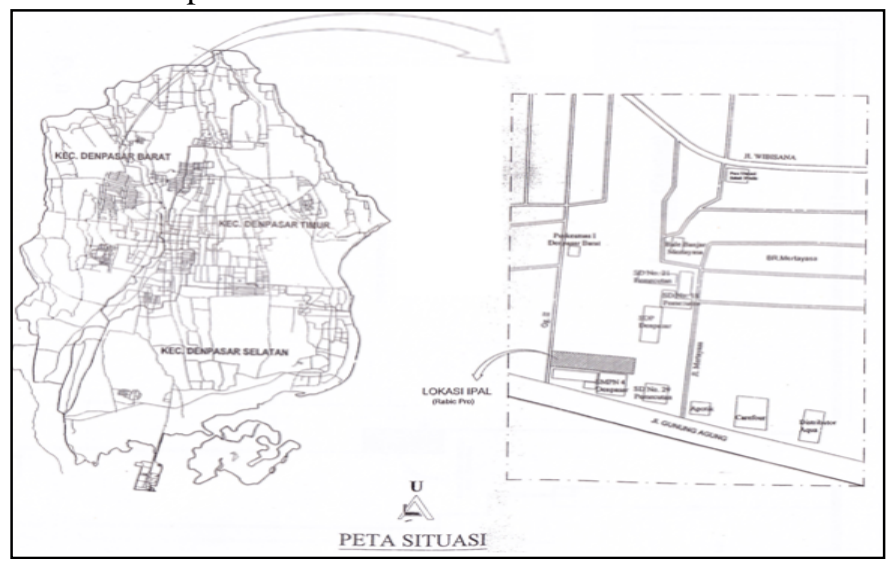

Gambar 1: Peta lokasi IPAL Desa Pemecutan Kaja

\section{B. Sistem Catu Daya IPAL Desa Pemecutan Kaja}

Sistem kelistrikan di IPAL ini yaitu hibrida antara PLTS dengan PLN. Daya dan energi listrik produksi PLTS di IPAL Desa Pemecutan Kaja didapatkan dari hasil perhitungan dan pengukuran. Besarnya daya listrik produksi PLTS merupakan hasil perhitungan antara tegangan (Vdc) dan arus (Idc) keluaran dari modul photovoltaic, sedangkan besar energi listrik produksi PLTS merupakan hasil perhitungan luasan di bawah grafik daya listrik produksi PLTS dan pengukuran besarnya energi listrik dari PLTS untuk memenuhi kebutuhan energi listrik di IPAL. Pada saat pengukuran tegangan (Vdc), arus (Idc) dan energi listrik PLTS ditambahkan keadaan lingkungan pada saat pengukuran. Keadaan lingkungan ini 
adalah keadaan cuaca, temperatur lingkungan dan kelembaban udara.

Tabel 1: Unjuk kerja PLTS Dan PLN Di IPAL Desa Pemecutan Kaja.

\begin{tabular}{|l|l|c|c|c|c|}
\hline \multirow{2}{*}{ No } & \multicolumn{1}{|c|}{ Variabel } & \multicolumn{4}{|c|}{$\begin{array}{c}\text { Rata-rata } \text { mengukuran pada hari } \\
\text { mingu }\end{array}$} \\
\cline { 3 - 6 } & \multicolumn{1}{|c|}{ I } & II & III & IV \\
\hline 1. & Tegangan per jam (V) & 12,36 & 12,58 & 12,53 & 14,84 \\
\hline 2. & Arus per jam (A) & 39,44 & 48,26 & 54,73 & 32,18 \\
\hline 3. & $\begin{array}{l}\text { Energi listrik PLTS yang } \\
\text { digunakan per hari (kWh) }\end{array}$ & 9,43 & 8,24 & 3,04 & 3,06 \\
\hline 4. & $\begin{array}{l}\text { Energi listrik PLN yang } \\
\text { digunakan per hari (kWh) }\end{array}$ & 0 & 0 & 0 & 0 \\
\hline 5. & $\begin{array}{l}\text { Kebutuhan energi listrik } \\
\text { IPAL per hari (kWh) }\end{array}$ & 9,43 & 8,24 & 3,04 & 3,06 \\
\hline 6. & $\begin{array}{l}\text { Temperatur lingkungan per } \\
\text { jam }\left({ }^{\circ} \mathrm{C}\right)\end{array}$ & 27,57 & 27,69 & 27,69 & 26,94 \\
\hline 7. & $\begin{array}{l}\text { Kelembaban Udara per jam } \\
(\% \mathrm{Rh})\end{array}$ & 75,64 & 75,43 & 75,43 & 78,50 \\
\hline
\end{tabular}

Besarnya penggunaan energi listrik di IPAL Desa Pemecutan Kaja dipengaruhi oleh volume limbah MCK dari warga. Energi listrik produksi PLTS merupakan perhitungan luasan di bawah grafik dari Gambar 2.

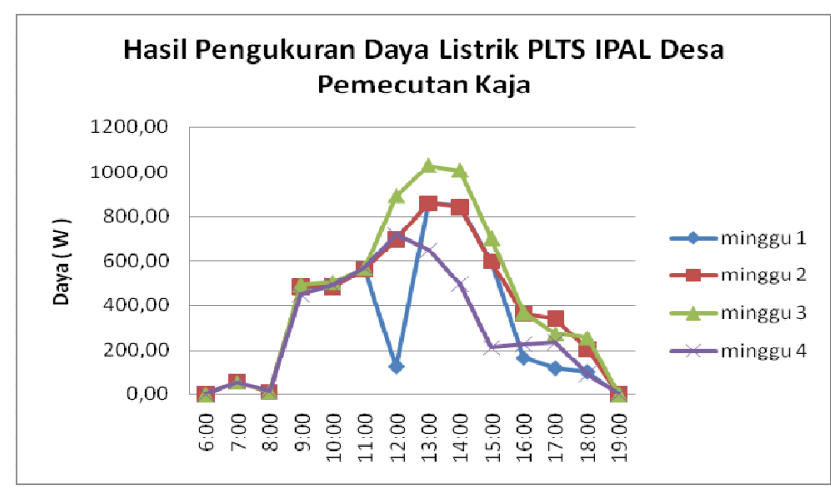

Gambar 2: Hasil pengukuran daya listrik di IPAL Desa Pemecutan Kaja

Bersadarkan hasil perhitungan luasan dibawah grafik pengukuran daya didapatkan produksi energi listrik per hari adalah sebagai berikut:

Tabel 2: Energi Listrik Produksi PLTS

\begin{tabular}{|l|l|c|}
\hline No. & Hari Minggu & Energi Listrik $($ Wh $)$ \\
\hline 1. & I & $29.849,42$ \\
\hline 2. & II & $21.788,03$ \\
\hline 3. & III & $25.623,22$ \\
\hline 4. & IV & $17.106,32$ \\
\hline \multicolumn{2}{|l|}{ Rata-rata energi } & $23.591,75$ \\
\hline
\end{tabular}

Perbedaan energi listrik yang dihasilkan PLTS disebabkan karena keadaan lingkungan yang berbeda pada saat melakukan pengukuran yaitu keadaan cuaca, temperatur lingkungan dan kelembaban lingkungan. Berdasarkan hasil pengukuran pada tabel 3 rata-rata temperatur lingkungan saat melakukan pengukuran adalah $27,57^{\circ} \mathrm{C}$ dengan kelambaban udara 75,64 \%Rh. Dengan keadaan cuaca pada waktu melakukan pengukuran, rata-rata energi yang dihasilkan yaitu 23.591,75 Wh atau 23,59 kWh.

\section{Pengelolaan IPAL Desa Pemecutan Kaja}

Pada awal tahun 2014 IPAL ini dikelola langsung oleh masyarakat Desa Pemecutan Kaja. IPAL ini dikelola oleh seorang ketua yang berasal dari warga banjar Tulang Ampiang P A R Arimbawa: studi pemanfaatan catu daya ......... dengan dibantu oleh dua orang warga sebagai petugas pemungut iuran dengan masing-masing bertugas di banjar Mertayasa dan di banjar Tulang Ampiang. Untuk biaya pemeliharaan, masyarakat dikenakan iuran perbulan sebesar Rp. 10.000,00. Perawatan sistem catu daya PLTS tidak pernah dilakukan. Sedangkan untuk bagian sipil dilakukan pembersihan apabila ada saluran yang tersumbat oleh sampah yang masuk saluran IPAL. Pada IPAL ini metode yang dapat digunakan untuk pembentukan lembaga pengelola pembangkit energi terbarukan adalah Participatory Action Research (PAR).

Pengelolaan IPAL Desa Pemecutan Kaja agar dapat berkembang diperlukan sumber daya manusia (SDM), perencanaan pengelolaan dan dana. Berdasarkan analisis model pengelolaan, IPAL ini baik untuk menerapkan organisasi garis dan staf. Gambar 4. adalah gambar struktur organisasi yang dapat digunakan IPAL Desa Pemecutan Kaja.



Penerapkan struktur organisasi garis dan staf di IPAL ini diharapan setiap pengurus dapat melakukan tugasnya berdasarkan keahlian yang dimilikinya. Setiap pengurus IPAL mempunyai tugas dan keahlian yang berbeda.

Pengelolaan IPAL dengan melakukan perawatan pada sistem kelistrikan dan bagian sipil IPAL yaitu dengan melakukan pembersihan pompa pada bak penampungan akhir dapat ditunjukan berdasarkan hasil pengukuran kebutuahn energi listrik IPAL.

Hasil pengukuran kebutuhan energi listrik IPAL per hari menunjukan hasil yang sangat berbeda pada pengukuran hari minggu I dan II dengan pengukuran hari minggu III dan IV. Pengukuran pada hari minggu I dan II dilakukan sebelum melakukan maintenance sistem kelistrikan dan bagian sipil IPAL, sedangkan pengukuran pada hari minggu III dan IV dilakukan setelah melakukan maintenance. Pada minggu ke XIV kembali dilakukan pengukuran kebutuhan energi listrik IPAL Desa Pemecutan Kaja.

Berdasarkan hasil pengukuran kebutuhan energi listrik di IPAL ini menunjukan perlukan dilakukan pegelolaan IPAL. Dengan dilakukan pengelolaan dengan melakukan pembersihan dapat mengurahi kebutuhan energi listrik yang akan mengurangi biaya operasional IPAL.

Untuk menjalankan pengelolaan IPAL Desa Pemecutan Kaja agar dapat berkembang diperlukan sumber daya manusia (SDM), perencanaan pengelolaan dan dana. Dana pada pengelolaan IPAL ini yang akan didapat dari iuran masyarakat sebagai pengguna IPAL.

p-ISSN:1693 - 2951; e-ISSN: 2503-2372 
Tabel 3: Kebutuhan Energi Listrik Per Hari (kWh) IPAL Desa Pemecutan

\begin{tabular}{|c|c|c|c|c|}
\hline \multicolumn{5}{|c|}{ Kaja. } \\
\hline No & Manintenance & $\begin{array}{c}\text { Waktu } \\
\text { pengukuran }\end{array}$ & $\begin{array}{c}\text { Energi listrik } \\
\text { IPAL per hari } \\
(\mathrm{kWh})\end{array}$ & $\begin{array}{l}\text { Rata-rata energi } \\
\text { listrik IPAL per } \\
\text { hari }(\mathrm{kWh})\end{array}$ \\
\hline \multirow[t]{2}{*}{1.} & \multirow{2}{*}{$\begin{array}{c}\text { Sebelum } \\
\text { maintenance }\end{array}$} & I. & 9,43 & \multirow[t]{2}{*}{8,835} \\
\hline & & II. & 8,24 & \\
\hline \multirow[t]{3}{*}{2.} & \multirow{3}{*}{$\begin{array}{c}\text { Setelah } \\
\text { maintenance }\end{array}$} & III. & 3,04 & \multirow[t]{2}{*}{3,05} \\
\hline & & IV. & 3,06 & \\
\hline & & XIV & 5,10 & 5,10 \\
\hline \multicolumn{4}{|c|}{$\mathrm{Ra}$} & 5,66 \\
\hline
\end{tabular}

\section{Biaya Siklus Hidup IPAL dan Iuran Masyarakat}

Pendanaan dalam pengoperasian IPAL ini seluruhnya bersumber dari iuran masyarakat Desa Pemecutan Kaja. Iuran masyarakat perbulan didapat berdasarkan perhitungan biaya siklus hidup IPAL desa pemecutan kaja selama 25 tahun. Biaya siklus hidup IPAL ini dihitung menggunakan persamaan berikut:

$\mathrm{LCC}_{\mathrm{IPAL}}=\mathrm{LCC}$ catu daya $+\mathrm{LCC}$ sipil + Operasional IPAL

Biaya operasional IPAL merupakan gaji pengurus IPAL Desa Pemecutan Kaja. Mengacu pada Peraturan Gubernur Nomer 69 Tahun 2014 tentang upah minimum kabupaten/kota, upah minium Kota Denpasar adalah sebesar Rp. 1.800.000,00 dengan jam kerja 8 jam perhari [15]. Dengan mempertimbangkan pekerjaan yang harus dikerjakan di IPAL ini dengan rentang waktu kerja $1-2$ jam kerja setiap harinya maka gaji yang diberikan pada pengurus IPAL perbulan sebesar 20\% dari UMK yaitu sebesar Rp. 360.000,00. Jadi biaya operasional IPAL selama setahun adalah sebagai berikut:

$$
\begin{aligned}
\text { Operasional IPAL } & =\text { Jumlah pengurus } \times \text { Gaji } \times 12 \text { bulan } \\
& =5 \times 360.000 \times 12 \\
& =\text { Rp. } 21.600 .000,00 / \text { tahun }
\end{aligned}
$$

Biaya operasional IPAL ini mengacu pada umur operasi PLTS adalah selama 25 tahun. Penentuan tingkat diskonto untuk menghitung nilai sekarang pada penelitian ini mengacu pada tingkat suku bunga kredit bank per Juni 2014 yaitu sebesar $11 \%$ [16]. Besar nilai sekarang (present value) untuk biaya operasional IPAL selama umur proyek 25 tahun dengan tingkat dikonto $11 \%$ dapat dihitung dengan rumus sebagai berikut:

$$
\begin{aligned}
P & =A\left[\frac{(1+i)^{n}-1}{i(1+i)^{n}}\right] \\
& =21.600 .000\left[\frac{(1+0,11)^{25}-1}{0,11(1+0,11)^{25}}\right] \\
& =21.600 .000\left[\frac{12,5855}{1,4944}\right] \\
& =\text { Rp. } 181.908 .720,00
\end{aligned}
$$

Bersadarkan perhitungan biaya siklus hidup catu daya, sipil dan biaya Operasional IPAL sehingga biaya siklus hidup IPAL adalah sebagai berikut:

$$
\begin{aligned}
\mathrm{LCC}_{\text {IPAL }}= & \text { LCC catu daya }+ \text { LCC sipil + Operasional IPAL } \\
= & 569.363 .516,58+763.094 .693,16+ \\
& 181.908 .720,00 \\
= & \text { Rp. } 1.514 .366 .929,74
\end{aligned}
$$

P A R Arimbawa: studi pemanfaatan catu daya .........
Apabila IPAL Desa Pemecutan Kaja hanya menggunakan catu daya PLN sehingga bersadarkan perhitungan biaya siklus hidup catu daya, sipil dan biaya Operasional IPAL. Biaya siklus hidup IPAL hanya menggunakan catu daya PLN dengan jumlah pengguna IPAL sebanyak $70 \mathrm{KK}$ adalah Rp. 978.302.903,76. Biaya siklus hidup IPAL hanya menggunakan catu daya PLN dengan jumlah pengguna IPAL sebanyak $200 \mathrm{KK}$ adalah Rp. 1.029.055.416,40. Biaya siklus hidup IPAL hanya menggunakan catu daya PLN dengan jumlah pengguna IPAL sebanyak $290 \mathrm{KK}$ adalah Rp. 1.064.369.106,36.

Perhitungan iuran perbulan masyarakat sama dengan biaya energi (cost of energy) IPAL yang ditentukan oleh biaya siklus hidup (LCC) IPAL, faktor pemulih modal (CRF) dan jumlah pengguna IPAL (AKK). Iuran perbulan masyarakat di IPAL Desa Pemecutan Kaja dapat dihitung dengan rumus sebagai berikut:

$$
C O E_{I P A L}=\frac{L C C \times C R F}{(A K K \times 12)}
$$

Faktor pemulih modal untuk mengkonversikan semua arus kas biaya siklus hidup menjadi biaya tahunan, dapat dihitung menggunakan rumus sebagai berikut:

$$
\begin{aligned}
C R F & =\frac{i(1+i)^{n}}{(1+i)^{n}-1} \\
& =\frac{0,11(1+0,11)^{25}}{(1+0,11)^{25}-1} \\
& =\frac{1,4944}{12,5855} \\
& =0,1187
\end{aligned}
$$

Setelah menghitung LCC,CRF dan jumlah pengguana IPAL adalah sebanyak $70 \mathrm{KK}$ maka iuaran pengguna IPAL perbulan $\left(\mathrm{COE}_{\mathrm{IPAL}}\right)$ adalah:

$$
\begin{aligned}
C O E_{I P A L} & =\frac{L C C \times C R F}{A K K \times 12} \\
& =\frac{1.514 .366 .929,74 \times 0,1187}{70 \times 12} \\
& =\frac{179.755 .354,56}{840} \\
& =\text { Rp. } 213.994,47 \\
& =\text { Rp. } 213.995,00 / \text { bulan }
\end{aligned}
$$

Apabila IPAL Desa Pemecutan Kaja hanya menggunakan catu daya PLN maka iuaran pengguna IPAL perbulan $\left(\mathrm{COE}_{\mathrm{IPAL}}\right)$ adalah:

$$
\begin{aligned}
C O E_{I P A L} & =\frac{L C C \times C R F}{A K K \times 12} \\
& =\frac{978.302 .903,76 \times 0,1187}{70 \times 12} \\
& =\frac{116.124 .554,67}{840} \\
& =\text { Rp. } 138.243,51 \\
& =\text { Rp. } 138.244,00 / \text { bulan }
\end{aligned}
$$

Iuran perbulan masyarakat sebasar Rp.213.995,00 pada tahun ke 25 investasi masyarakat telah kembali dengan nilai total payback period sebesar Rp.5.456.508,65. p-ISSN:1693 - 2951; e-ISSN: 2503-2372 
Berdasarkan perhitungan biaya siklus hidup yang sama dengan iuran perbulan Rp.10.000,00 belum dapat menutupi biaya operasional IPAL tiap tahunnya. Pada tahun pertama nilai arus kas bersih IPAL sebesar Rp. -25.434.550,00.

Mengacu pada Peraturan Daerah Provinsi Bali No. 2 Tahun 2011 tentang retibusi jasa umum, pengolahan limbah cair kota denpasar yaitu Denpasar Sawerage Development Project $(D S D P)$. Untuk klasifikasi pelanggan rumah tangga dibedakan menjadi 3 tipe. Tipe A merupakan perumahan yang dimukanya terdapat jalan yang kelebarannya dibawah 7 meter dikenakan tarif sebesar Rp.15.000 per bulan, tipe B dengan jalan yang kelebarannya di antara 7 - 10 meter dikenakan tarif sebesar Rp.20.000 per bulandan tipe C dengan jalan yang kelebarannya diatas 10 meter dikenakan tarif sebesar Rp.25.000 per bulan. Berdasarkan klasifikasi pelanggan pada IPAL Desa Pemecutan Kaja termasuk pelanggan rumah tangga tipe A dengan tarif Rp.15.000 per bulan. Dengan perhitungan biaya siklus hidup yang sama dengan iuran perbulan Rp. 15.000,00 tidak dapat menutupi biaya operasional IPAL tiap tahunnya. Pada tahun pertama nilai arus kas bersih IPAL sebesar Rp. -21.234.550,00.

Pada perencanaan pembangunan IPAL Desa Pemecutan Kaja jumlah pengguna IPAL akan terus bertambah dengan dilakukannya pemasangan baru secara bertahap. Pengguna IPAL ini direncanakan akan terpasang sebanyak $200 \mathrm{KK}$. Berdasarkan perhitungan biaya siklus hidup IPAL Desa Pemecutan Kaja selama 25 tahun dengan jumlah pengguna IPAL sudah terpasang semua sebanyak $200 \mathrm{KK}$ maka iuran perbulan masyarakat adalah sebesar Rp.74.899,00 dan apabila IPAL Desa Pemecutan Kaja hanya menggunakan catu daya PLN adalah sebesar Rp. 50.896,00. Dengan iuran perbulan masyarakat sebasar Rp.74.899,00, pada tahun ke 25 investasi masyarakat telah kembali dengan nilai total payback period sebesar Rp. 5.471.667,79.

Berdasarkan hasil perbandingan produksi energi listrik PLTS terhadap kebutuhan energi listrik IPAL, dengan produksi energi PLTS sebesar 23,591 kWh/hari dapat memenuhi kebutuhan energi listrik IPAL dengan jumlah pengguna IPAL sebanyak $290 \mathrm{KK}$. Berdasarkan perhitungan biaya siklus hidup IPAL Desa Pemecutan Kaja selama 25 tahun dengan jumlah pengguna IPAL sudah terpasang semua sebanyak $290 \mathrm{KK}$ iuran perbulan masyarakat adalah sebesar Rp.51.654,00 dan apabila IPAL Desa Pemecutan Kaja hanya menggunakan catu daya PLN adalah sebesar Rp.36.305,00. PLTS dengan iuran perbulan masyarakat sebasar Rp.51.654,00 pada tahun ke 25 investasi masyarakat telah kembali dengan nilai total payback period sebesar Rp.5.457.519,26. Biaya energi listrik menggunanakan sumber energi terbarukan memerlukan biaya yang lebih mahal dibandingkan dengan pembangkit listrik konvensional atau menggunakan bahan bakar fosil.

\section{SIMPULAN}

Berdasarkan studi pemanfaatan catu daya hibrida PLTS 3,7 kWp dan PLN dengan mempertimbangkan hasil pengukuran, perhitungan, dan analisis dari penelitian yang telah dilakukan di IPAL Desa Pemecutan Kaja, maka dapat disimpulkan bahwa :
1. Hasil studi pemanfaatan catu daya hibrida PLTS dan PLN di IPAL Desa Pemecutan Kaja dapat memenuhi kebutuhan energi listrik IPAL dengan rata-rata energi listrik yang dihasilkan PLTS per hari yaitu 23.591,75 Wh atau 23,59 kWh dengan harga energi sebesar Rp.7.766,25/kWh.

2. Dengan melakukan maintenance pada IPAL Desa Pemecutan Kaja dapat mengurangi kebutuhan energi listrik IPAL yaitu dari $8.835 \mathrm{Wh}$ per hari menjadi 3.050 Wh per hari.

3. Iuran perbulan masyarakat bervariasi tergantung dari jumlah pengguna IPAL dimana dengan jumlah pengguna IPAL sebanyak $70 \mathrm{KK}$ besaranya iuran perbulan adalah sebesar Rp. Rp.213.995,00, dengan pengembangan sesuai perencanaan IPAL jumlah pengguna menjadi sebanyak 200 KK besaranya iuran adalah Rp.74.899,00 serta dengan pengembangan IPAL sesuai produksi energi listrik PLTS dengan jumlah pengguna IPAL menjadi sebanyak $290 \mathrm{KK}$ besaranya iuran adalah Rp.51.654,00.

\section{REFRENSI}

[1] Kananda, "Konsep Pengaturan Aliran Daya Untuk PLTS Tersambung KeSistem Grid Pada Rumah Tinggal," Jurnal Nasional Teknik Elektro, vol. 2, no.2, pp. 65-71, Sept. 2013.

[2] Rifan, "Optimasi Pemanfaatan Energi Listrik Tenaga Matahari di Jurusan Teknik Elektro Universitas Brawijaya," Jurnal EECCIS, vol. 6, no. 1 , pp. 44-48, Jun. 2012.

[3] I. N. S. Kumara, "Pembangkit Listrik Tenaga Surya Skala Rumah Tangga Urban Dan Ketersediaannya Di Indonesia," Jurnal Teknologi Elektro, vol. 9, no.1, pp. 60-75, Januari - Juni 2010.

[4] I. N. S. Kumara, W. G. Ariastina, I. W. Sukerayasa, I. A. D. Giriantari, "1 Mwp Grid Connected PV Systems In The Village Of Kayubihi Bali; Review On Location's Characteristics And Its Technical Specifications," Information Technology and Electrical Engineering (ICITEE) International Conference on, pp. 306-311. doi: 10.1109/ICITEED.2013. 6676258. 2013.

[5] I. N. S. Kumara, W. G. Ariastina, I. W. Sukerayasa, I. A. D. Giriantari, "On The Potential And Progress Of Renewable Electricity Generation In Bali," International Conference in Technology and Electrical Engineering (ICITEE), vol., no., pp.1-6, Oct. 2014.

[6] I. K. A. Setiawan, "Analisis Unjuk Kerja Pembangkit Listrik Tenaga Surya (Plts) Satu MWP Terinterkoneksi Jaringan di Kayubihi Bangli," Jurnal Teknologi Elektro, vol. 13, no. 1, 2014.

[7] Yogianto, "Configuration Hybrid Solar System (PV), Wind Turbine, And Dieseld," ICPERE (International Conference Power Engineering and Renewable Energy), Diakses tanggal 14 januari 2014.

[8] I. D. A. Santiari, "Studi Pemanfaatan Pembangkit Listrik Tenaga Surya Sebagai Catu Daya Tambahan Pada Industri Perhotelan di Nusa Lembongan Bali,” Tesis, Universitas Udayana, Bali, Indonesia, 2011.

[9] A. Kadir, Energi: Sumber Daya, Inovasi, Tenaga Listrik dan Potensi Ekonomi, edisi 3. Jakarta, Indonesia: Universitas Indonesia. 2010.

[10] Hasan, "Perancangan Pembangkit Listrik Tenaga Surya Di Pulau Saugi," Jurnal Riset dan Teknologi Kelautan (JRTK), vol. 10, no. 2, pp. 169-180, 2012.

[11] A. S. Sampeallo, 2006. Pembentukan Kelembagaan Pengelolaan Pembangkit Energi Terbarukan Di Perdesaan. Universitas Nusa Cendana Kupang. Diakses tanggal 17 juni 2014.

[12] Foster, R. 2010. Solar Renewable Energy And The Environment. Boca Raton, FL, CRC Press.

[13] A. A. Lazou, A. D. Papatsoris, "The Economics Of Photovoltaic StandAlone Resdidential Households: A Case Study For Various European And Mediterranean Locations," Solar Energy Material \& Solar Cell 62:411-427. 2000. (nama jurnal, vol, no tidak jelas)

[14] B. A. A. Abdel-Ghani, "Techno-Economic Evaluation Of Smallvillages In Palestine By Centralized And Decentralized Pvsystem," Tesis, An-Najah National University, Palestine, 2008.

[15] BKD. 2015. Peraturan Gubernur Nomer 69 Tahun 2014 tentang upah minimum kabupaten/kota. BKD Propinsi Bali.

[16] BI. 2014. Suku Bunga Dasar Kredit. Bank Indonesia. 